\title{
Dos modelos televisuais em vídeos na web: desdobramentos midiáticos do programa de receita culinária ${ }^{1}$
}

\section{On televisual models in web videos: media developments of TV cooking shows}

Caroline Cavalcanti de Oliveira²

\footnotetext{
1 Uma versão preliminar deste artigo foi apresentada durante o XXXVII Congresso Brasileiro de Ciências da Comunicação da Intercom (Sociedade Brasileira de Estudos Interdisciplinares da Comunicação), realizado em Foz do Iguaçu de 1 a 5 de setembro de 2014.

2 Docente na FAE Centro Universitário (Curitiba). Doutoranda e mestre no Programa de Pós-Graduação em Comunicação e Linguagens da Universidade Tuiuti do Paraná. Especialista em história da arte no século XX pela Escola de Música e Belas Artes do Paraná (EMBAP). E-mail: carocavalcanti@gmail.com.
} 
Este artigo apresenta reflexões relacionadas à percepção de modelos televisuais em vídeos concebidos para internet. Como estratégia de investigação, são analisados desdobramentos do texto de receita culinária no audiovisual através de sua observação na história da televisão e em vídeos produzidos para a web. Para tanto, a pesquisa contemplou aspectos dos formatos adotados pelos programas de receitas na TV e por vídeos com o tema em sites de compartilhamento, avaliando especialmente como vêm se manifestando esses conteúdos na web sob influência de um paradigma televisual. Os textos de receita são interpretados neste estudo como produtos culturais, um recorte que ilustra debates envolvendo televisão e vídeo, mídia e internet, e tecnologias digitais.

\section{Palavras-chave}

Televisão, vídeos na web, receita culinária. 
This paper presents reflections related to the application of televisual models in videos conceived to the internet, via a research strategy that analyzes developments of cooking recipes in both: history of television and videos produced to web. The research regards the influence of the televisual paradigm (specially the format of TV cooking shows) in the content of videos available in sharing websites. The cooking recipes are considered in this study as cultural products, establishing debates concerning television and video, media and internet, and digital technologies.

\section{Keywords}

Television, web videos, culinary recipe. 
Sob influência de uma onda de consumo, a ampliação do espaço dedicado ao universo da cozinha na indústria editorial e na mídia tem alcançando o ambiente da internet, motivando a diversificação de produções acerca do tema, seja em blogs, aplicativos ou vídeos concebidos especialmente para a web. Com relação aos vídeos, levantamento realizado para este artigo possibilitou notar que, de um modo geral, o paradigma televisual é bastante presente nas receitas apresentadas na internet. Diante dessa percepção, procura-se analisar como receitas culinárias vêm sendo disponibilizadas na web, comparativamente com o que ocorre na TV: são observadas instâncias em que a receita culinária é apresentada no vídeo, em diferentes suportes e tecnologias, como produto de parâmetros assumidos culturalmente. Reflete-se, assim, acerca da adoção de novas linguagens e narrativas - em especial, nas relações envolvendo o modelo do programa de receitas na televisão e o vídeo no ambiente da internet.

\section{Receita culinária como objeto cultural: modelos textuais}

Das anotações transmitidas de uma geração à outra, passando por demonstrações na TV e chegando ao uso dos contemporâneos aplicativos, a composição da receita culinária revela a permanência de um modelo que sofreu poucas alterações de tempos remotos aos dias atuais, apesar de avanços tecnológicos em suas formas de divulgação. Essa característica pode ser observada em publicações, produtos de mídia, blogs e aplicativos de receitas, e sobretudo de vídeos na internet que, apesar da estrutura distinta da TV, parecem tender a conservar o modelo específico do meio que a antecede.

Diferentes contextos, avanços tecnológicos, padrões que se repetem: ao compreender a noção de cultura a partir da definição de Williams, é possível entender razões para esse encontro. A definição proposta pelo autor parte do entendimento de que cultura "são significados compartilhados, o produto de todo um povo, e sendo oferecidos os significados individuais, o produto de toda uma experiência pessoal e social comprometida de um homem" (WILLIAMS, 1989, p. 8, tradução nossa) ${ }^{3}$. Para Williams, ainda, é "estúpido e arrogante supor que qualquer desses significados pode de algum modo ser prescrito; eles são feitos pela vivência, feitos e refeitos, de modos que não podemos saber antecipadamente." (WILLIAMS, 1989, p. 8, tradução nossa) ${ }^{4}$.

\footnotetext{
3 Do original: "(...) common meanings, the product of a hole people, and offered individual meanings, the product of a man's whole commited personal and social experience".

4 Do original: "(...) stupid and arrogant to suppose that any of these meanings can in any way be prescribed; they are made by living, made and remade, in ways we cannot know in advance".
} 
Nessa acepção, pode-se pensar cultura como um modo, ou modos de vida, assimilados, não necessariamente ensinados formalmente, mas que se constroem de modo inconsciente; que representam e se refletem no comportamento geral. Padrões culturais pressupõem constantes redefinições, adaptações, atualizações, e compreender o mundo a partir de objetos pode revelar não somente o quanto estes podem definir cultura, mas como também podem ser por ela definidos.

Por um lado, "nenhuma leitura dos objetos culturais recentes ou antigos pode ser completa se não se considerar relevantes, em termos de resultados, a 'lógica' intrínseca do material e os procedimentos técnicos que lhe dão forma" (MACHADO, 2001 , p. 11, grifo nosso). No entanto, não se deve descartar a constância das redefinições, adaptações e atualizações que fundamentam a noção de cultura; os ajustes e (re)organizações ininterruptos que a constituem. Os modelos assumidos pelos objetos culturais e a forma como evoluem decorrem de preparo para que aconteçam. Experimentamos a lógica e a técnica no momento em que nossa relação com os objetos vai de encontro ao preparo cultural: a redefinição de um objeto cultural é, também, uma redefinição de nosso comportamento em relação a ele.

Em linhas gerais, são presentes na composição de um texto de receita culinária (i) a apresentação do objetivo (dado pelo nome ou descrição do prato que intitula a receita), (ii) os ingredientes a serem utilizados e sua quantidade prevista, e (iii) o modo de combinação destes ingredientes. A essa estrutura, pode-se acrescentar uma descrição ou representação do resultado a ser obtido, além de variantes da fórmula (como dicas para efeitos alternativos, por exemplo), e mesmo sugestões ou opções para a apresentação e acompanhamento do prato. Vale ressaltar que não há exatamente uma regra na composição de tais representações da receita; no entanto, historicamente, é comum encontrar uma distribuição desse passo a passo em (i), (ii) e (iii), sucessivamente, em suportes diversos.

Linearmente, o texto de receita impresso foi sendo moldado a partir de particularidades já apresentadas no manuscrito ${ }^{5}$ e, mesmo que antes mais rebuscado ou menos objetivo, parece conservar a forma básica de origem como estrutura predominante. A organização característica desse texto acabou migrando para outros meios, mesmo com a inclusão da oralidade e da imagem em movimento (ou seja, a receita no rádio e na TV). Desse modo, nas suas variadas manifestações - seja impresso num livro ou apresentado na televisão - podese observar, em termos compositivos, que geralmente se segue um padrão de escrita ${ }^{6}$ para a receita culinária (Figura 1 ).

$5 \mathrm{E}$ que, historicamente, tem provável origem na forma oral da transmissão de receitas, seja no círculo familiar ou profissional.

6 Não se refere aqui à escrita como texto impresso, mas um formato de composição que compreende igualmente a oralidade, como o programa de rádio ou televisão, entre outras produções audiovisuais. 


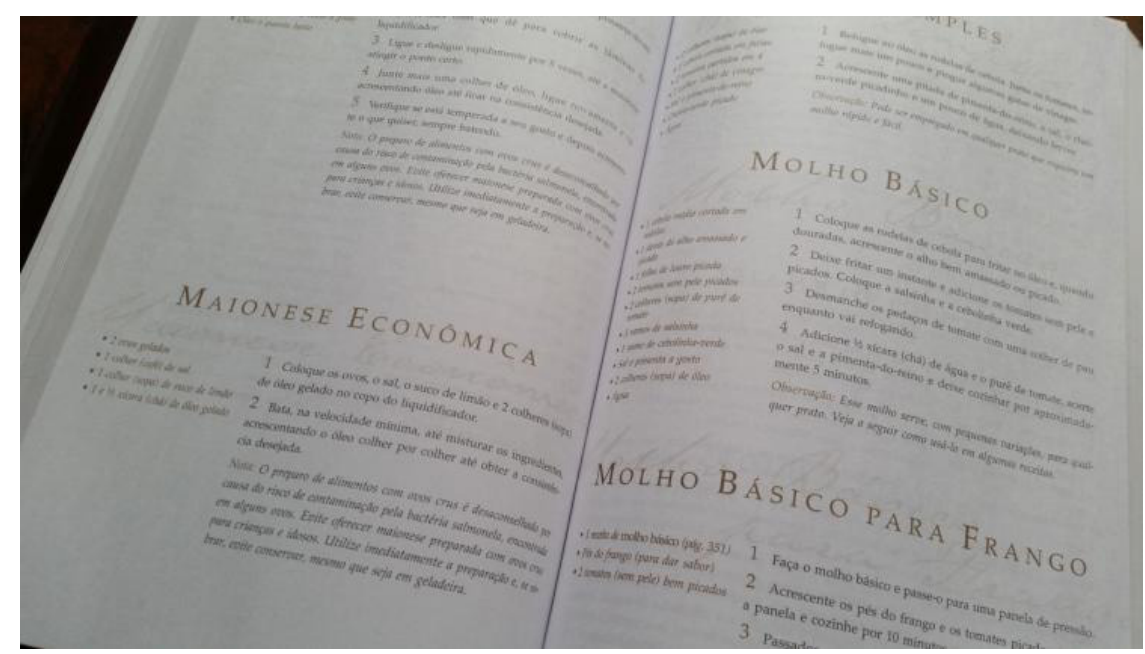

Figura 1 - Páginas de um livro de receitas culinárias e a estrutura predominante do texto: título, ingredientes e modo de preparo. Fonte: BENTA, 2003, p. 350-351 (fotografia nossa).

O rádio, em certa medida, relacionou o aspecto informal da fala com a estrutura formal da receita (COLLINS, 2009, p. 15): quando no rádio, meio que conta essencialmente com a oralidade, a combinação de ingredientes acomodou inovações como o acréscimo de figuras de linguagem (o uso de onomatopeia e hipérbole, por exemplo, que conferiram mais dinamismo ao texto) e a admissão de comentários (atribuindo mais personalidade ao locutor-apresentador, o que culminou com a noção de chef-celebridade na TV7). Com a migração do programa de receitas do rádio para a TV, o espaço disponível, gradualmente preenchido com inserções de publicidade, desenvolveu-se sob forma de esquetes cômicos, filmes ou programas promocionais que anunciavam aparatos e utensílios domésticos ${ }^{8}$.

Como forma de apresentar qualidades e funcionalidades dos aparatos e utensílios, tais veiculações acabaram por trazer demonstrações culinárias para a televisão, o que rapidamente ganhou contornos do programa de receitas como concebido atualmente. Em seu aspecto mais essencial, o ambiente televisual revelou-se propício ao desenvolvimento desse formato; conformando imagem, movimento e oralidade, o texto de receita encontrou, na TV, um espaço conveniente para se estabelecer. Assim sendo, o nicho já percebido pelo rádio foi

\footnotetext{
7 A imperativa presença de um rosto na televisão, que culminou com a existência do chef-celebridade, está ligada ao caráter comercial do texto de receita, com origens na era do rádio e no início da televisão. Se antes a presença do apresentador tinha por objetivo conferir confiabilidade a produtos diversos, dada inclusive por testemunhais, essa noção deu condições para a criação do que se propõe aqui chamar de chef-celebridade: alguém conhecido na mídia que, para além do sucesso como apresentador e chef na TV, converte-se em marca e passa a ditar comportamentos.
} 
importado e desenvolvido pela TV, deixando marcas profundas na maneira como nos relacionamos com a receita (Figura 2), mesmo após o advento das tecnologias digitais.

A aparição do programa de receitas na televisão coincide com o início de suas transmissões; em meados dos anos 1940, já se tinha a oportunidade de ler uma receita com recursos próprios (e dinâmicos) da oralidade e de degustar o passo a passo da imagem em movimento na realização de um prato na TV. Mas, como lembra Marialva Barbosa, se "a página do livro pressupõe o manuseio, a virada da folha, a linearidade [...] do começo em direção ao fim, a televisão como objeto material induz a distintas maneiras de ler. Por outro lado, acionam-se processos cognitivos totalmente diversos" (BARBOSA, 2007, p. 7, grifo da autora). Observese, portanto, como a receita culinária é admitida na configuração da TV.

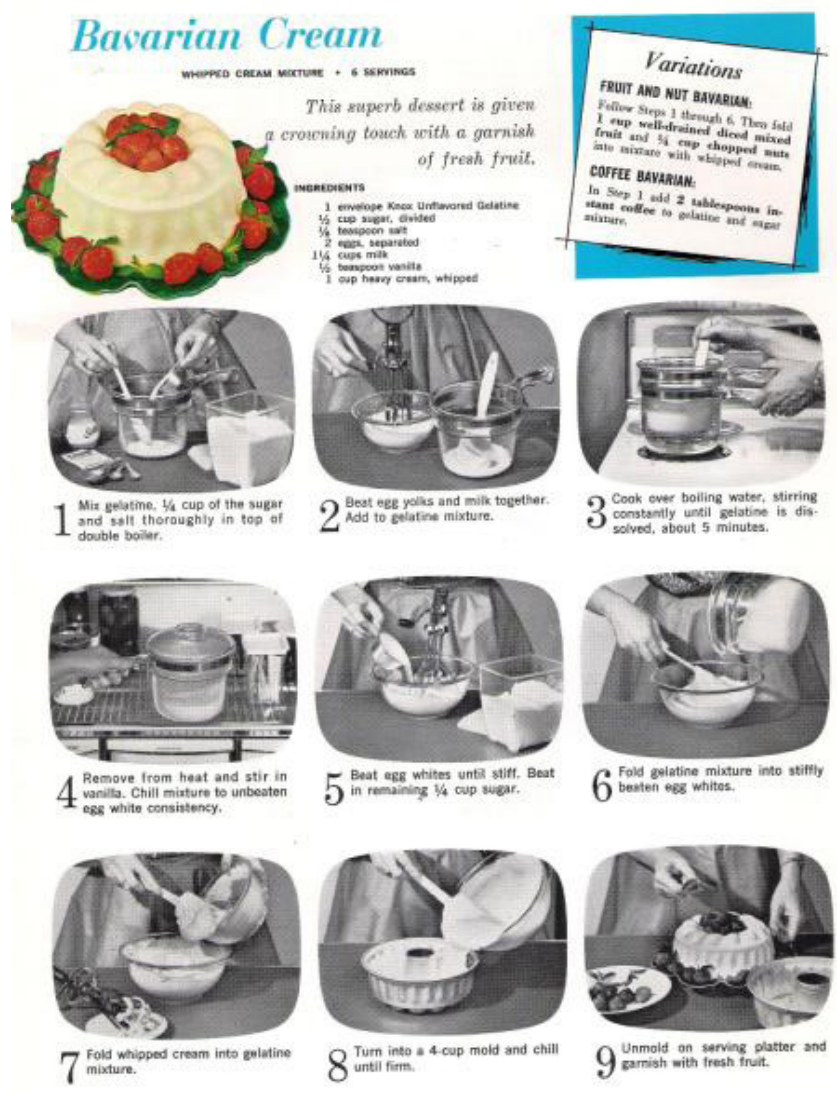

Figura 2 - Página de livro de receitas com ilustração de passo a passo simulando enquadramentos de TV. Fonte: KNOX, 1963, p. 12.

Primeiramente, a existência de uma narrativa tipicamente televisual (BARBOSA, 2007, p. 3) remete à ideia de padronização. Nas instâncias internas dos programas de TV, nas inserções publicitárias, vinhetas, e nas relações entre 
tais manifestações audiovisuais ${ }^{9}$, há uma linguagem característica da televisão, independente da emissora ou do conteúdo veiculado. Segundo Barbosa (2007, p. 6), "[a] narrativa da TV usa o repertório limitado do olho, produzindo padronizações. São essas padronizações que dominam as emissões. Daí a repetição de fórmulas, de situações, de imagens, de diálogos e de gestos".

Enquanto forma, em sua essência, o programa de receitas admite variações, mas conserva uma estrutura fundamental que compreende, por um lado, a já mencionada composição (i) apresentação do objetivo, (ii) ingredientes, e (iii) combinação dos elementos, remetendo à forma característica do texto de receita; e por outro, o paradigma televisual que envolve abertura, desenvolvimento e encerramento de um programa, com a inserção comercial. Nesse aspecto, podese dizer que a forma assumida pelo programa de culinária na TV é sancionada pela estrutura de origem do texto de receita em relação à narrativa televisual: o conteúdo (o ato culinário) conforma-se à previsão de espaços comerciais na TV, quer na dinâmica interna do programa, com o anúncio direto ou indireto de produtos (a forma seria propícia ao anúncio de marcas quando da utilização de ingredientes e equipamentos na execução da receita), quer na sua separação em blocos por intervalos comerciais (o programa encontraria nos intervalos uma simulação de espera oportuna para o tempo de cozimento).

\section{Modelos televisuais e o espaço para a receita na web}

Quando uma nova tecnologia é desenvolvida, de alguma maneira recorremos a práticas com materialidades anteriores para experimentar possíveis usos do objeto cultural mais recente. As formas de preparo e o aperfeiçoamento da relação com os objetos são condições culturais para os desdobramentos desses usos. Isso não quer dizer, obviamente, que uma materialidade ou tecnologia contemporânea signifique sua superioridade ou maior relevância em relação àquela que a antecede (WOLTON, 2012, p. 81), tampouco que objetos culturais sejam fruto de mera "combinação e desenvolvimento de formas anteriores" (WILLIAMS, 2003, p. 39, tradução nossa) $)^{10}$ : "uma característica importante dos novos sistemas [é] que eles

\footnotetext{
9 A observação do modo como essa narrativa se organiza é essencial para perceber como se dá a experiência de TV, e como as partes que a compõem são subordinadas a um arranjo próprio: embora os programas de televisão, individualmente, possam ter propostas específicas, deve-se lembrar que sua configuração narrativa foi moldada com o passar dos anos, especialmente em relação à grade de programação. Não poderíamos pensar em televisão sem considerar a inserção publicitária como "parte da experiência" (MARQUIONI, 2013, p. 109). Considerar esses fatores inerentes ao ambiente televisual remete ao conceito de "fluxo" dado por Williams (2003, p. 77-120): para o autor, a forma como se apresenta a televisão pressupõe a noção de fluxo, que qualifica a integração entre os elementos - itens (2003, p. 77-120) - que a compõem (basicamente, programas e inserções publicitárias, entre outras manifestações audiovisuais). E, no nosso entendimento, ainda que cada componente integrante do fluxo tenha uma dinâmica interna, é seu pertencimento ao todo, ou sua existência em fluxo, que possibilita a experiência televisual. Pode-se dizer que, na contemporaneidade, mesmo o zapping integra-se ao fluxo na medida em que se tornou intrínseco ao ato de assistir TV.
} 
oferecem oportunidades para novas relações culturais que os sistemas anteriores não disponibilizavam" (WILLIAMS, 1983 apud MARQUIONI, 2013, p. 66). Assim como a experiência do público com a TV, em sua origem, esteve bastante marcada pelo apelo à oralidade, atributo típico do rádio, a atitude com a internet parece também supor os produtos culturais que a antecedem como uma maneira de experimentar e desenvolver sua própria estrutura narrativa.

Quanto à experiência, pode-se dizer que de um ou outro modo o preparo cultural acompanhado da longa relação com o impresso, o rádio e a TV impulsivamente nos compele a olhar para a tela suporte da internet como se estivéssemos diante de uma revista ou jornal mais dinâmicos, uma outra experiência radiofônica, uma nova televisão. O uso que se faz hoje das capacidades tecnológicas, mais modernas na experiência com a internet que com a mídia impressa, o rádio ou a TV convencional, daria a falsa impressão de supremacia daquela em relação a essas práticas culturais anteriores não fosse o juízo de que cultura é algo que se reconfigura de modo permanente (WILLIAMS, 1989); os ajustes e (re)organizações ininterruptos inerentes às práticas culturais não supõem necessariamente superação de objetos anteriores.

Levando-se em consideração a intensidade com que nossa relação com a web vem se desenvolvendo pela penetrabilidade da internet, esse sistema a priori de transmissão ${ }^{11}$ (divulgação e compartilhamento) explicitamente realiza uma espécie de apropriação de estruturas anteriores, graças à sua capacidade funcional (WOLTON, 2012, p. 98) de comunicação e pela facilidade com que tais conteúdos se integraram a esse ambiente. Para Wolton, somente com o sucesso da internet é que houve seu entendimento como mídia (WOLTON, 2012). Nesses termos pode-se entender, portanto, que o desempenho em relação às tecnologias digitais acabou por abrigar modelos prévios e assim ampliar práticas culturais anteriores: sem pretensões de criar uma estrutura narrativa específica, a forma obtida por modelos precedentes converteu-se, com uso das tecnologias digitais, em novas práticas culturais.

Nesse panorama, em acréscimo à capacidade de transmissão permitida pela internet, é compreensível nos depararmos, por exemplo, com a infinidade de blogs de receitas culinárias que surgiram como uma versão adaptada do modelo que constitui a forma escrita da receita. Propriedades da redação impressa são facilmente identificadas na observação da forma assumida por esses blogs, que parecem constituir mais uma mudança de suporte do texto que um avanço tecnológico na forma de apresentação desse conteúdo: linearmente, a receita é

11 Para Wolton, "a net não é uma mídia. É um formidável sistema de transmissão e de acesso a um número incalculável de informações" (2012, p. 99, grifo do autor). 
apresentada de maneira análoga à de um livro ou de uma revista, por exemplo, contando na internet com amplo espaço para ilustrações ou vídeos - mesmo os aplicativos conservam o critério de coerência da receita impressa (Figura 3).

Partindo do entendimento de Wolton, ao pensarmos no uso que já se faz das tecnologias digitais e da internet, não há como negar a tendência à integração de atividades, antes distintas, num mesmo suporte (ainda que pressuponham um diferente lugar cultural): a "mudança não é somente técnica, é também cultural, uma vez que não haverá mais diferenças entre atividades separadas durante séculos" (WOLTON, 2012, p. 94). Isso provavelmente se deve à observação fundamental feita pelo autor de que "as mídias encontraram sua inscrição social e cultural enquanto que as novas tecnologias ainda não" (WOLTON, 2012, p. 96, grifo nosso).

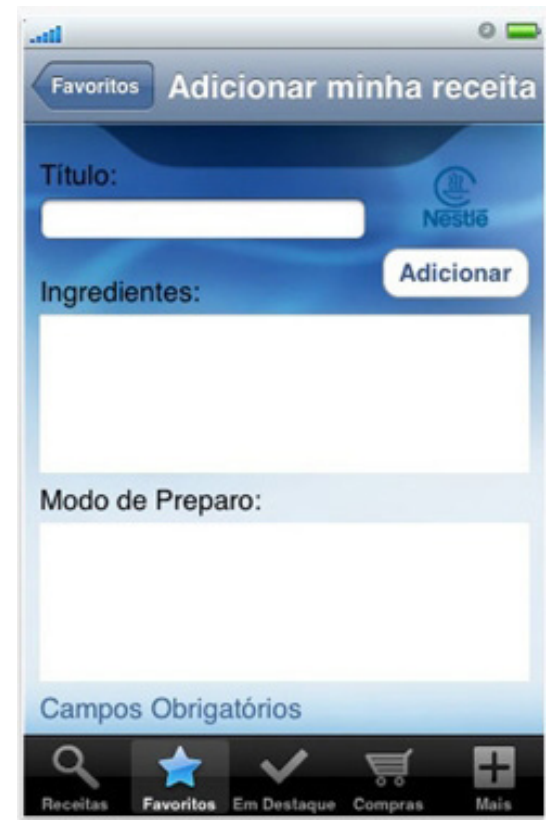

Figura 3 - Aplicativo de receitas da marca Nestlé, com campos padronizados a serem preenchidos pelo consumidor/usuário. Fonte: imagem capturada da rede. ${ }^{12}$

Não à toa, portanto, deve-se ter presente a percepção de que é necessário preparo cultural para o aperfeiçoamento da relação com tecnologias diversas; seria utópico e audacioso pensar que, com um sistema como a internet, que vem se desenvolvendo com tanta rapidez e que tão visivelmente conforma características de estruturas anteriores, o desempenho seria diferente: "mesmo a melhor e mais útil tecnologia do mundo não pode impor-se a um público não preparado" (KERCKHOVE, 2009, p. 21). De modo espontâneo tendemos a dilatar nossas

12 Disponível em: http://info.abril.com.br/noticias/blogs/download-da-hora/iphone/aplicativo-da-nestle-e-para-aqueles-quegostam-de-cozinhar/. Acesso em: 05 nov. 2014. 
relações com objetos culturais, cuja permeabilidade de contornos - sua constituição é também decorrente de nossa experiência com eles - acaba por imprimir marcas em nosso comportamento com outros objetos, outras tecnologias.

Similaridades de produções para internet com o formato televisual podem ser observadas em parte por serem bastante evidentes, mas também pelo grande número de vídeos com essas características disponibilizados na web, conforme apontou o levantamento realizado para este artigo ${ }^{13}$. A observação de vídeos de culinária e gastronomia ${ }^{14}$ nos sites selecionados revelou uma tônica inclinação na web em se reproduzir padrões televisuais do programa de receitas, em alusão ao modelo já estabelecido pela TV, mesmo com a ocorrência de serialidade (ou organização em episódios). Percebe-se, sobretudo, que tais vídeos, mesmo se apresentando em suportes diversos - e cronologicamente posteriores, principalmente - da TV convencional, são marcados pela insistência no empréstimo de uma narrativa que funciona na TV. Nesse sentido, pode-se dizer que características presentes na produção de vídeos especificamente para a web indicam a forte influência de uma cultura televisual no ambiente digital da internet.

Ao incorporar elementos televisuais, vídeos de receitas concebidos para a internet vêm apresentando, entre as propriedades bastante similares às de produções que antecedem o meio, fundamentalmente uma herança de ordem técnica e de formato. Tecnicamente, dada a forma como são abordados planos, enquadramentos, movimentos de câmera, entre outros atributos e efeitos audiovisuais, de modo geral, grande número de vídeos respondem à estrutura predominante no modelo vigente da televisão. Quanto ao formato, ainda que a concepção de programa, como objeto cultural, esteja em princípio relacionada à configuração própria de mídias como o rádio e a TV, o apelo a essa estrutura no ambiente da web suscita analogias com o que se entende como item na composição de fluxo televisual (WILLIAMS, 2003, p. 77-120): considerar que esses produtos se comportam como itens na web reforça o atual comportamento diante da internet como mídia.

A criação de canais no ambiente da internet é aspecto bastante curioso na sua relação instituída com as mídias. Mas tal associação não deve incorrer na percepção de sites, por exemplo, enquanto (outras) emissoras: a diferença fundamental entre canais da televisão e de sites de compartilhamento de vídeos é que nesses últimos, pela característica do sistema, ocorre mais uma proposição de agrupamento, de coleção, que uma seleção integrada a uma estrutura predominante - ou à ordem

13 Optou-se por observar dois sites de divulgação e compartilhamento de vídeos populares atualmente: YouTube e Vimeo, com a busca pelas palavras-chave receita, culinária e gastronomia.

14 Quando usados como mecanismos de busca, os dois termos dirigem a vídeos de receitas. Não são exploradas possíveis distinções ou semelhanças entre nomenclaturas neste artigo. 
própria do fluxo, no caso da TV. O que não se pode negar é que a denominação canal para uma divisão temática ou de conteúdo decorre de mecanismos de assimilação, logo deriva do preparo cultural que delineia a experiência com a web. Ao considerarmos a constituição de canais, estamos realizando um empréstimo de terminologia, e não de estrutura, da TV para a internet.

Nesse aspecto, pode-se constatar, em canais nos sites pesquisados, que a internet é bastante empregada como suporte digital dos mesmos vídeos de programas produzidos para televisão (em geral uma captação do internauta, editada e compartilhada). É comum a criação de canais pelo internauta ora para abrigar vídeos por ele coletados (avulsos ou em outros canais, por vezes no próprio site), ora para propor vídeos por ele produzidos (o que não o impede de realizar as duas opções). Canais oficiais (canais na web de programas de culinária originalmente produzidos para a TV, ou canais de seus apresentadores) comumente trazem para internet uma versão reduzida ou adaptada desses programas na TV. Como exemplo de ações com essa característica, pode-se citar os canais de Nigella Lawson nos sites Vimeo ${ }^{15}$ e YouTube ${ }^{16}$ que apresentam vídeos de caráter promocional e com frações editadas do material que constitui o programa de TV Nigelíssima, incluindo captações de making of (mas nunca um episódio na íntegra).

Ainda é possível verificar um ponto importante, e que se destaca das atividades mais comuns nesses sites de compartilhamento de vídeos: a criação de programas específicos para canais da web. O canal Foodtube, de Jamie Oliver para o site YouTube $^{17}$ é bom exemplo: o material lançado exclusivamente para esse canal da web é constituído de episódios estrelados pelo próprio Jamie Oliver, além de vídeos apresentados por outros cozinheiros (famosos ou não), restaurateurs e outros que poderiam ser considerados webchefs ${ }^{18}$. Aqui, não apenas há um aproveitamento da já existente fama do apresentador e do sucesso de seus programas na TV, como também é nítida a intenção de um arranjo tipicamente televisual. Em essência, tais vídeos poderiam ser episódios de um programa de televisão, veiculados na internet.

Um dos aspectos mais relevantes na ressonância do programa de receitas da TV em vídeos na web diz respeito à presença do apresentador, ou do chefcelebridade. Ainda que nos vídeos da web convivam em paralelo celebridades

15 Disponível em: https://vimeo.com/channels/nigella. Acesso em: 06 mai. 2014.

16 Disponível em: http://www.youtube.com/channel/UC7jM43otyf2_Ye_DBrQYKfg. Acesso em: 06 mai. 2014.

17 Disponível em: http://www.youtube.com/user/JamieOliver. Acesso em: 06 mai. 2014.

18 O termo, em alusão ao conceito de chef-celebridade esboçado anteriormente, é proposto no entendimento de que seria um novo empréstimo de nomenclatura do universo televisual para a web, ao conformar características similares. 
e anônimos, a atuação desses últimos indica uma tentativa de simular o desempenho de apresentadores conhecidos da TV, mesmo em tentar tornarse uma versão sua na web. $E$, apesar da diferença que reside na raiz da forma comunicacional, já há indícios de que alguns desses webchefs estejam ficando conhecidos no ambiente da internet.

A figura do apresentador em programas de culinária e gastronomia na TV nos remete à importância da oralidade e de sua pertinência no ambiente midiático: "[é] a voz funcionando em conjunto com as imagens que ativa os diversos lugares de possibilidade de diálogo da televisão com o público" (BARBOSA, 2007, p. 6). Na web, contudo, mesmo que tenhamos bastante presente a tentativa de acomodação da figura de um apresentador, ao que parece, outra forma de sua abordagem da receita vem se desenvolvendo. Em algumas produções recentes, como é o caso da série The Miam Factory ${ }^{19}$, a voz já não parece ser necessária, e da mesma maneira o rosto que apresenta a receita (Figuras 4 e 5): o apresentador na web, além de aparentemente não precisar mais ter uma voz, quando tem um rosto, está por vezes desfocado - enquadramentos com apenas as mãos, ou ainda sem evidência visual de alguém que executa a receita têm se mostrado cada vez mais comuns em vídeos de receitas culinárias na web. Se a internet não pressupõe exatamente relação com um público (é uma interação direta), o rosto e em especial essa abordagem da oralidade na web podem não ter a mesma validade que na televisão, o que parece se traduzir no aumento do número de vídeos de receitas produzidos para a web que exploram outras expressões de imagem e som como alternativas para a presença do apresentador (ou narrador), e da oralidade.

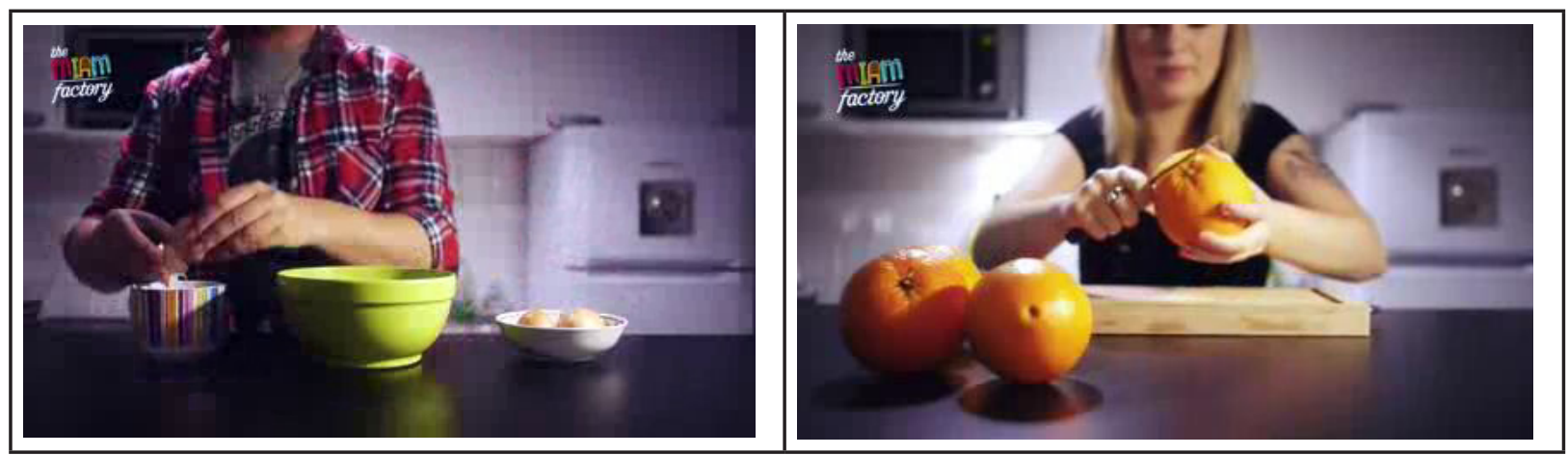

Figuras 4 e 5 - Ausência do rosto e distorção do foco do apresentador na série The Miam Factory. Fonte: imagens capturadas na rede. ${ }^{20}$ 


\section{Modelo televisual ou um vir a $\operatorname{ser}^{21}$ das narrativas na web?}

Embora o padrão televisual ainda pareça prevalecer na web ao se observar quantitativamente vídeos produzidos especialmente para essa forma de transmissão, os diferentes aspectos que vêm se destacando no material disponibilizado mais recentemente apontam para novos modos do vídeo na web. Animação, efeitos sonoros e visuais, gráficos e de montagem, ganharam espaço e se apresentam como tendência em vídeos de receitas produzidos para compartilhamento. Se no programa de receitas na TV essa forma de composição se restringia a vinhetas e aberturas de programas, os efeitos audiovisuais agora migram para o conteúdo do vídeo na web, diferenciando-o esteticamente do formato televisual que o antecede. Em decorrência dessa característica, é evidente a íntima relação que alguns vídeos parecem estabelecer com o apelo estético presente em videoclipes musicais e mesmo com a publicidade e, ainda que obedecendo à lógica intrínseca do modelo (com as etapas descritas anteriormente) da receita como ocorre na TV, essas produções começam a apresentar composições de caráter mais poético que informativo ou didático, com uma forma aparentemente mais voltada às estéticas da cozinha (ou mesmo do vídeo), dadas pelo conteúdo da receita. É possível encontrar evidências de um arranjo eminentemente estético nos vídeos produzidos e compartilhados pelo chef Christopher Andrew Cooke 22 , ou ainda pela internauta Sónia Garcia23, ambos no site Vimeo.

Essa abordagem contemporânea com o vídeo de receita parece responder à forma descentralizada de produção e transmissão: a acessibilidade a recursos diversos e a possibilidade de compartilhamento na web abriram espaço para um período de contato e experimentação com tecnologias digitais que, com o passar do tempo, vêm moldando novas performances com esses objetos culturais. As variações de composição que começam a caracterizar o vídeo de receita produzido para a internet indicam, portanto, uma alteração não apenas na estrutura interna dessas produções. As sutis diferenças que percebemos surgir nesses vídeos sugerem mudanças de comportamento diante de materialidades tecnológicas.

Levando em conta a noção de preparo cultural, se considerarmos que o desempenho em relação aos objetos culturais é inerente à sua própria (re)definição, pode-se dizer que estamos vivendo um momento distinto da experimentação que vinha marcando nossa relação com as tecnologias digitais. A gama de recursos

\footnotetext{
21 Termo proposto por Marquioni e Barbosa (2013) originalmente para tratar das perspectivas da TV Digital interativa em relação à TV convencional e outros meios midiáticos. Para os autores, o "vir a ser dos meios de comunicação é, antes de tudo, um vir a ser das práticas culturais do público" (Marquioni e Barbosa, 2013, p. 65, grifos nossos).
} 
audiovisuais, incrementada por avanços tecnológicos e explorada continuamente, e as mudanças na forma e na relação com o vídeo de receita, podem estar constituindo um formato narrativo do digital na web. Nesse sentido, ainda que seja uma suposição a partir de uma tendência observada em produções mais recentes, é na promoção de novas relações entre o verbal e o não-verbal que pode residir uma narrativa tipicamente digital.

A relação com a internet não difere de outras práticas culturais. Assim como o comportamento com a televisão pressupõe fases de desenvolvimento (WILLIAMS, 2003, p. 23) - ou seja, não se vê (a) TV hoje da mesma maneira que quando surgiu, bem como se vive um processo de novos usos da TV na era digital - o mesmo se dá com as formas de produção de vídeo e com a internet ${ }^{24}$. E, da mesma maneira que ocorreu com o rádio e a TV, podemos estar, neste momento, experimentando avanços em vídeos produzidos para a web. Na internet, assim como ocorre com a televisão, pode-se dizer que "o contínuo temporal instaurado por sua narrativa está na dependência direta das possibilidades oferecidas pela tecnologia" (BARBOSA, 2007, p. 5).

A conjugação de modelos textuais com novos modos de ver evidencia a importância de objetos culturais anteriores na relação com materialidades tecnológicas mais recentes. A permanência de modelos televisuais em outros suportes e as transformações que começam a sugerir uma linguagem específica da web (e sua possível alusão em outros meios) confirmam a coexistência dos modos e dos meios, marcando a espontaneidade das apropriações em práticas culturais. É com essas percepções do vídeo de receita produzido para a internet em relação ao modelo televisual que se faz aqui empréstimo da expressão vir a ser, proposta por Marquioni e Barbosa (2013, p. 65): sob a ótica da cultura torna-se possível pensar em uma nova perspectiva das formas do vídeo, um vir a ser das narrativas na web como expressão da contemporaneidade. E, culturalmente, esse vir a ser é refletido na relação com o texto de receita e da forma como ele é apresentado, por sucessivas gerações tecnológicas.

\footnotetext{
24 Não esqueçamos que, como a TV, o computador (suporte da internet por excelência) também passou pela fase do tubo e hoje se constitui como uma tela plana, de moldura quase invisível e, da mesma forma, foi da visualidade em preto-e-branco para o colorido. A diferença de rumos tomados pela forma, na contemporaneidade, parece ser no tamanho. A TV, de um modo geral, cresce em sua dimensão. Nos anos 1950, o tamanho médio de um visor não ultrapassava 14 polegadas, enquanto que hoje a procura no varejo para aparelhos de TV parece apontar para uma escala proporcionalmente mais avantajada (na arquitetura, fala-se em home theater, não mais em sala de estar). Quanto ao computador, que antes ocupava salas inteiras, teve que reduzir substantivamente em tamanho para chegar ao ambiente doméstico. Do kit básico do PC doméstico em meados dos anos 1990 , composto por um gabinete, um monitor, um teclado e um mouse (se considerarmos a inclusão da internet, acrescente-se uma linha telefônica e um modem), passamos ao limite de um único aparato, portátil, em que é possível processar informação, visualizar, selecionar, digitar e comunicar (falar, ouvir, enviar mensagens), além de funções como captação e edição de imagens, que antes pertenciam a produtores oficiais. Não obstante, muitos modelos de smartphone hoje vêm com a função TV.
} 


\section{Referências}

AUMONT, J. Dicionário teórico e crítico do cinema. São Paulo: Papirus, 2010.

BARBOSA, M. "Televisão, narrativas e restos do passado". Revista E-Compós, v.8, abr. 2007. Disponível em: http://www.compos.org.br/seer/index.php/e-compos/ article/view/ 138/139. Acesso em: 26 mai. 2014.

BENTA, D. Comer bem: 1001 receitas de bons pratos. 75a. ed. rev. e ampl. São Paulo: Companhia Editora Nacional, 2003.

COLLINS, K. Watching what we eat. The evolution of television cooking shows. New York: Continuum, 2009.

KERCKHOVE, D. A pele da cultura. Investigando a nova realidade eletrônica. São Paulo: Annablume, 2009.

KNOX on-camera recipes. A completely new guide to gel-cookery. New York: Knox Gelatine Co., 1963.

MACHADO, A. Máquina e imaginário: o desafio das poéticas tecnológicas. São Paulo: Edusp, 2001.

MARQUIONI, C. E. TV digital interativa brasileira: redefinições culturais e interações midiáticas em tempos de migração tecnológica (e-book). Curitiba: UTP, 2013.

MARQUIONI, C. E.; BARBOSA, M. "TV digital: estruturas de sentimento na televisão do vir a ser". Comunicação, Mídia e Consumo. São Paulo, ano 10, v. 10, n. 27, abr. 2013, p. 57-74. Disponível em: http://revistacmc.espm.br/index.php/revistacmc/ article/view/410. Acesso em: 23 jun. 2014.

WILLIAMS, R. "Culture is ordinary". In: Resources of hope: culture, democracy, socialism. London: Verso, 1989, p. 3-18.

WILLIAMS, R. Television: technology and cultural form (e-book). London: Routledge, [1974] 2003.

WOLTON, D. Internet, e depois? Uma teoria crítica das novas mídias. Porto Alegre: Sulina, 2012. 